\title{
Sexual Dimorphism of Mandibular Ramus in an Egyptian Sample: A Radiographic Study
}

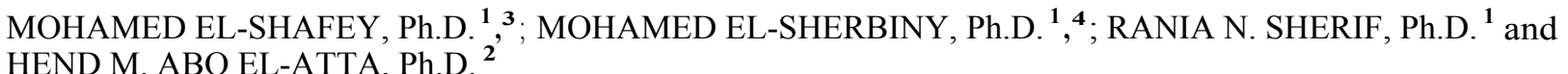 \\ The Departments of Anatomy \& Embryology ${ }^{1}$ and Forensic Medicine \& Clinical Toxicology ${ }^{2}$, Faculty of Medicine, \\ Mansoura University, The Department of Anatomy and Embryology, Fakeeh College for Medical Sciences, Jeddah, KSA ${ }^{3}$ and \\ The Department of Forensic and Toxicology, Faculty of Medicine, Al-Maarefa University, Riyadh, Saudi Arabia ${ }^{4}$
}

\begin{abstract}
Background: Determination of the sex is an important step in the identification of skeletal remains especially in missing persons and mass disasters. Mandible, being a strong bone that is difficult to damage and disintegrate, is an important tool in sex determination.

Aim of the Study: The present study aimed to evaluate accuracy of mandibular metric standards for estimating sexual dimorphism.

Methods: The study was conducted on 90 males and 92 females of Egyptian sample. Orthopantomographs were taken for evaluating eleven mandibular metric parameters. Four models were adopted by the stepwise discriminant analysis test to define the best predictor of sex discrimination in the Egyptian population sample.
\end{abstract}

Results: All parameters were found to be significantly different between both sexes; and the most dimorphic parameters were coronoid height, projective height, and mandibular canal length, followed by mandibular notch depth and condylar height. Meanwhile the least variables were gonial angle and bicondylar length.

Conclusion: This study proves that mandibular measurements on digital radiograph are useful in sex determination.

Key Words: Mandibular ramus - Sexual dimorphism - Orthopantomographs - Egyptian.

\section{Introduction}

SEX determination is considered main stage in unidentified skeletons in medico legal cases as a part of establishing personal identity from skeletal remains, which is not always easily and correctly performed, especially in cases of mass disaster such as in explosions, warfare and aircraft crashes due to skeletal fragmentation [1], as many of the parameters of human identification such as age and height are basically sex reliant [2] .

Correspondence to: Dr. Mohamed El-Shafey, E-Mail: drmohamedshafey@gmail.com
The skull is considered as the second most dimorphic portion to identify sex with accuracy up to $92 \%$; following the pelvis [2]. Mandible, a strong bone, which is difficult to disintegrate and damage, plays a pivotal role in gender determination. It retains its shape and is considered as the most durable facial bone that remains well preserved and to produce healthier diagnostic fragments; compared to other more spongy bones $[3,4]$ In various populations, marked significant differences between female and male mandibles have been reported [5] and this can help with prediction of the sex in unidentified mandibles. The mandible contains many distinctive variables that can be used for sex identification, even in badly burnt bodies. The dimorphism of the mandible is influenced by the forces of mastication that is associated with greater morphological changes in shape and size and remodeling, especially the ramus of the mandible; such changes differ greatly during the growth between males to females $[4,6]$.

Reliability of sex determination from human remains relies basically on: The completeness of the remains (up to $100 \%$ accuracy in cases of complete skeleton); and the inherent grade of sexual dimorphism in a given people [7]. One of the best challenging tasks for forensic science is to detect the mysterious human skeletal remnants of deceased individuals. Morphological features of bones remains extreme important tool for medico-legal assessment for the sex study.

Metric standards for skeletal sex determination are considered a superior measure due to their objectivity, exactness, creativity; and their lower level of inter and intra-observer reliability; compared to other descriptive parameters [7]. Many studies reported that the adult mandible could be 
used to recognize both sex and population resemblance compared to other standard analytical techniques with good results [8].

The sexual discriminate function that characterizes one particular people cannot be applied to another set; owing to the greatness of sex-related changes that differ considerably among local peoples [9]. Despite several studies in many different areas worldwide, the characteristic features of mandibular sexual dimorphism are not well set in Egypt until now. An Egyptian study was conducted by Kharoshah et al., 2010 [10] for sex determination from the mandible using spiral CT scan, thus this study was conducted to compare measurement taken by this method with the previous finding taken by $\mathrm{CT}$ in Egyptian sample to validate the obtained results.

Panoramic radiographs are widely used in dentistry. Panoramic radiography accuracy in providing anatomic measurements for the angular and linear measurements on the mandible has been reported $[5,11,12]$.

The present study is designed calculate the mandibular measurements in an Egyptian population sample and determine their accuracy in estimating sexual dimorphism through orthopantomographic study.

\section{Material and Methods}

A study was conducted with 90 males and 92 females of the Egyptian population collected from the records of the Faculty of Dentistry outpatient clinic, University of Mansoura, Dakahlia, Egypt; with complete dentition during the period from March 2016 to August 2016. Cases with pathological, fractured or developmental abnormalities of the mandible were excluded. There was no mere exposure to X-ray. However, patients' information was kept confidential.

This study was conducted on 90 male and 92 females with mean age $37.62 \pm 10.07 \mathrm{y}$ for males and $37.04 \pm 11.03 y$ for females with no significant differences between both $(p=0.716)$.

Orthopantomographs were captured by Kodak 8000C Digital Panoramic and Cephalometric System $(73 \mathrm{kVp}, 12 \mathrm{~mA}, 13.9 \mathrm{~s})$. Measurements of the mandibular ramus were recorded using Master View 3.0 software.

The following parameters were defined and measured as the following Figs. $(1 A, B)$ :

$M x B$ : Maximum ramus breadth: The distance between the most anterior point on the mandibular ramus and a line connecting the most posterior point on the condyle and the angle of jaw $[2,7,13]$

$M n B$ : Minimum ramus breadth: Smallest anterior-posterior diameter of the ramus $[2,13]$.

$\mathrm{CdH}$ : Condylar height: Height of the ramus of the mandible from the most superior point on the mandibular condyle to the tubercle, or most protruding portion of the inferior border of the ramus $[2,7]$.

$\mathrm{CrH}$ : Coronoid height: Projective distance between coronoid and lower wall of the bone $[2,7]$.

ND: Mandibular notch depth: The distance along a perpendicular line from the deepest point of the ramus notch concavity [14].

$P H$ : Projective height of ramus is the distance between the highest point of the mandibular condyle and lower margin of the bone [2,7].

GA: Gonial Angle: The angle between two tangents which are drawn from inferior border of the mandible and posterior borders of condyle (i.e. angle between the ramus and corpus of the mandible) $[15]$

$B C L$ : Bicondylar Length: Distance between two condylion [10].

$B G L$ : Bigonial Length: Distance between two gonions [10].

MBL: Mandibular Base Length: The length of the curved line connecting the right gonion(Mentum, lowest point on the bony outline of the mandibular symphysis); and left gonion [16]

McL: Mandibular canal length: The sum of all the lengths of the divided sections of the mandibular canal (the mandibular canal was divided into short sections $5 \mathrm{~mm}$, and the length of each part approximated to its arc length) [17].

Different models were calculated by stepwise discriminant analysis to estimate the most discriminatory model to differentiate between males and females.

\section{Statistical analysis:}

SPSS statistical analysis program (Version 16.0) was used to analyze the data using numbers and percent for qualitative data and using mean and standard deviation for quantitative data. Student- $t$-test was used to establish that a major difference occurred between the male and female mean values for each of the measurements, and then the direct and stepwise analyses were performed on the significant variables. Univariate analysis was performed on each of the variables in order to obtain demarking points (average of 
male and female mean values) that could be used for fragmentary bones in which all parameters are not measurable. Discriminant analysis with "the stepwise feature being used to the variable or combination of variables that best discriminates between sexes. Direct analysis of individual variables was performed to develop formulae to allow sex determination from fragmentary remains.
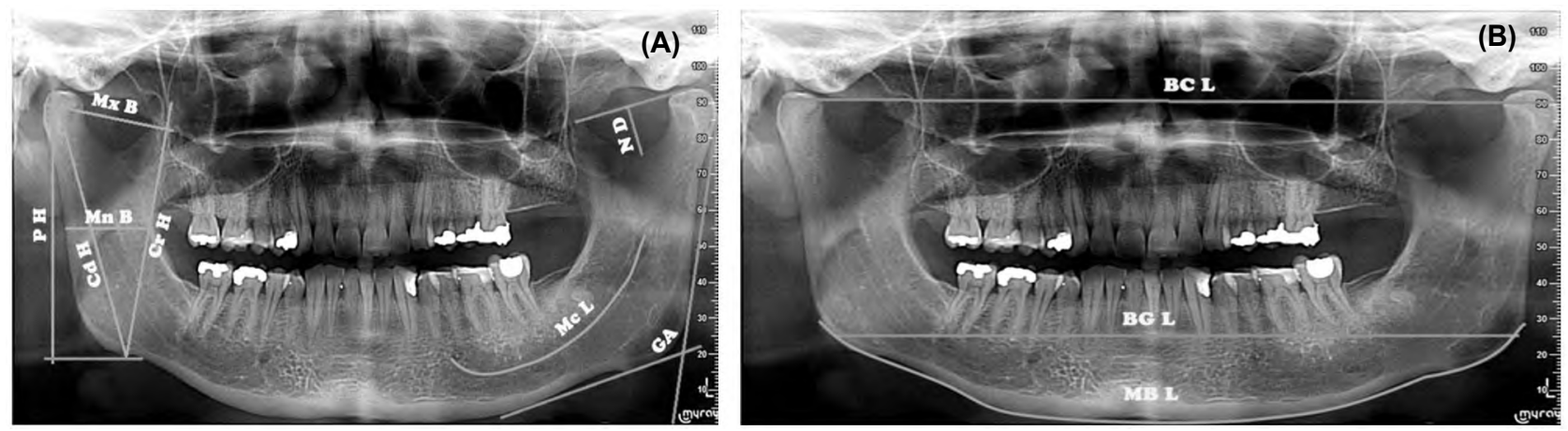

Fig. (1A,B): Mandibular metric standard parameters on orthopantomographs.

\section{Results}

Descriptive statistics of all mandibular metric parameters $(n=11)$ and associated univariate $F$ ratio for both sexes were shown in (Table 1). All measurements were found to be statistically significant between the sexes $(p<0.05)$. Comparison of mean values shows that all parameters were higher for male measurements than females. The F-statistic values indicate that mandibular parameters expressing the greatest dimorphism were coronoid height, projective height, mandibular canal length, condylar height, and mandibular notch depth (Table 1).

Table (1): Comparison of mandibular metric parameters in males $(n=90)$ and female $(n=92)$ subjects.

\begin{tabular}{|c|c|c|c|c|c|c|}
\hline Parameter & $\begin{array}{c}\text { Total } \\
(\text { Mean } \pm \text { SD })\end{array}$ & $\begin{array}{c}\text { Male } \\
(\text { Mean } \pm \text { SD) }\end{array}$ & $\begin{array}{c}\text { Female } \\
(\text { Mean } \pm \text { SD })\end{array}$ & $\begin{array}{l}\text { Wilki's } \\
\text { lambda }\end{array}$ & $\begin{array}{c}\text { F- } \\
\text { value }\end{array}$ & $\begin{array}{c}p- \\
\text { value }\end{array}$ \\
\hline $\mathrm{MxB}$ & $3.79 \pm 0.46$ & $3.95 \pm 0.45$ & $3.65 \pm 0.43$ & .876 & 24.081 & $0.0001 *$ \\
\hline $\mathrm{MnB}$ & $2.6 \pm 0.32$ & $2.63 \pm 0.33$ & $2.5 \pm 0.33$ & .875 & 24.351 & $0.0001 *$ \\
\hline $\mathrm{CdH}$ & $6.23 \pm 0.74$ & $6.47 \pm 0.69$ & $5.89 \pm 0.69$ & .829 & 35.096 & $0.0001 *$ \\
\hline $\mathrm{CrH}$ & $5.79 \pm 0.66$ & $6.06 \pm 0.58$ & $5.52 \pm 0.62$ & .759 & 53.916 & $0.0001 *$ \\
\hline PH & $6.67 \pm 0.76$ & $6.99 \pm 0.72$ & $6.31 \pm 0.63$ & .803 & 41.691 & $0.0001 *$ \\
\hline ND & $1.18 \pm 0.23$ & $1.27 \pm 0.23$ & $1.09 \pm 0.19$ & .840 & 32.306 & $0.0001 *$ \\
\hline $\mathrm{McL}$ & $7.05 \pm 0.77$ & $7.36 \pm 0.7$ & $6.68 \pm 0.69$ & .803 & 41.611 & $0.0001 *$ \\
\hline GA & $111.55 \pm 11.19$ & $109.74 \pm 12.24$ & $113.36 \pm 9.51$ & .970 & 5.301 & $0.02 *$ \\
\hline BCL & $17.87 \pm 1.21$ & $18.24 \pm 1.7$ & $17.51 \pm 1.25$ & .910 & 16.835 & $0.0001 *$ \\
\hline BGL & $16.29 \pm 1.18$ & $16.71 \pm 1.83$ & $15.88 \pm 1.1$ & .875 & 24.276 & $0.0001 *$ \\
\hline MBL & $19.86 \pm 1.69$ & $20.35 \pm 1.55$ & $19.38 \pm 1.68$ & .878 & 23.673 & $0.0001 *$ \\
\hline $\begin{array}{l}\text { MxB : Max } \\
\text { MnB : Mini } \\
\text { CdH : Con } \\
\text { CrH : Coro }\end{array}$ & $\begin{array}{l}\text { Ramus Breadth. } \\
\text { Ramus Breadth. } \\
\text { leight. } \\
\text { leight. }\end{array}$ & $\begin{array}{l}\text { PH : Proj } \\
\text { ND : Man } \\
\text { McL : Man } \\
\text { GA : Gon }\end{array}$ & $\begin{array}{l}\text { Ieight. } \\
\text { Notch Depth. } \\
\text { Canal Length. } \\
\text { le. }\end{array}$ & $\begin{array}{l}\text { BCL } \\
\text { BGL } \\
\text { MBL } \\
*\end{array}$ & $\begin{array}{l}\text { : Bicodylar L } \\
\text { : Bigonial Le } \\
\text { : Mandibular } \\
\text { Significant }\end{array}$ & ength. \\
\hline
\end{tabular}

Table (2) shows that direct discriminant functions were calculated for all studied models; discriminant equations, group centroids and sectioning points. Discriminant scores were obtained by multiplying each variable with its unstandardised coefficient, summing them and adding in the constant. Scores greater than the sectioning point are classified as male and smaller values as female. The model with the highest predicted accuracy (model II) was calculated as follows:

$\mathrm{D}_{\text {male }}=100.137+1.600$ (coronoid height $)+$ 9.443 (mandibular canal length) + 6.787 (bicodylar length) +.460 (mandibular notch depth).
$\mathrm{D}_{\text {female }}=-87.625+.537$ (coronoid height $)+$ 8.118 (mandibular canal length) +7.162 (bicodylar length) +-3.734 (mandibular notch depth).

In this model the sectioning point was found to be -0.097 .

This study investigated the prediction accuracy of four different models: Model I (all mandibular metric parameters were studied); model II (four metric parameters chosen by stepwise analysis); model III (three metric parameters according to Saini et al., [7] model IV (studied four metric 
parameters according to Kharoshah et al., [10]. The stepwise discriminant analysis test define the best interpreters of sex discrimination (Table 3).

The study identified model II as a most accurate predictor of sex determination which uses coronoid height, mandibular canal length, bicondylar length and mandibular notch depth (overall predictive accuracy is $76 \%$ ). It could properly recognize males in $76.1 \%$ and females in $23.8 \%$ of cases. Incorrect identification of males occurred in $23.9 \%$ versus $76.2 \%$ in females as shown in Table.

Table (2): Linear and stepwise discriminate analysis of different models.

\begin{tabular}{|c|c|c|c|c|c|c|c|}
\hline Variable & Male & Female & $\begin{array}{c}\text { Raw } \\
\text { coefficients }\end{array}$ & $\begin{array}{l}\text { Standardized } \\
\text { coefficients }\end{array}$ & $\begin{array}{c}\text { Structure } \\
\text { coefficients }\end{array}$ & Centroids & $\begin{array}{l}\text { Sectioning } \\
\text { point }\end{array}$ \\
\hline \multicolumn{8}{|l|}{ Model I: } \\
\hline $\mathrm{MxB}$ & -19.498 & -19.890 & .273 & .134 & .522 & Male $=$ & -0.1 \\
\hline $\mathrm{MnB}$ & 20.539 & 19.585 & .664 & .206 & .525 & 0.669 & \\
\hline $\mathrm{CdH}$ & 4.485 & 3.806 & .472 & .321 & .630 & Female $=$ & \\
\hline $\mathrm{CrH}$ & 12.980 & 11.911 & .744 & .471 & .781 & -0.769 & \\
\hline $\mathrm{PH}$ & -6.806 & -5.821 & -.685 & -.467 & .687 & & \\
\hline ND & -.739 & -4.337 & 2.503 & .533 & .605 & & \\
\hline $\mathrm{McL}$ & 5.252 & 3.989 & .879 & .609 & .686 & & \\
\hline GA & 1.711 & 1.706 & .003 & .035 & -.245 & & \\
\hline BCL & 3.944 & 4.569 & -.434 & -.610 & .436 & & \\
\hline BGL & 4.033 & 3.980 & .037 & .052 & .524 & & \\
\hline MBL & 3.552 & 3.426 & .088 & .153 & .517 & & \\
\hline Constant & -232.949 & -219.739 & & -9.241 & & & \\
\hline \multicolumn{8}{|l|}{ Model II: } \\
\hline $\mathrm{CrH}$ & 1.600 & .537 & .764 & .483 & .807 & Male $=$ & -0.097 \\
\hline ND & -.460 & -3.734 & 2.354 & .501 & .709 & 0.647 & \\
\hline $\mathrm{McL}$ & 9.443 & 8.118 & .953 & .660 & .625 & Female $=$ & \\
\hline BCL & 6.787 & 7.162 & -.270 & -.379 & .451 & -0.744 & \\
\hline Constant & -100.137 & -87.625 & & -9.042 & & & \\
\hline \multicolumn{8}{|l|}{ Model III: } \\
\hline $\mathrm{MxB}$ & 2.634 & 2.401 & .201 & .099 & .968 & Male $=$ & -0.081 \\
\hline $\mathrm{MnB}$ & 14.626 & 13.856 & .664 & .206 & .650 & 0.540 & \\
\hline $\mathrm{CrH}$ & 10.472 & 8.953 & 1.310 & .829 & .647 & Female $=$ & \\
\hline constant & -55.749 & -44.583 & & -9.666 & & -0.621 & \\
\hline \multicolumn{8}{|l|}{ Model IV: } \\
\hline $\mathrm{CdH}$ & 7.702 & 6.634 & 1.093 & .743 & .927 & Male $=$ & -0.069 \\
\hline GA & 1.271 & 1.277 & -.006 & -.068 & -.360 & 0.454 & \\
\hline $\mathrm{MnB}$ & 10.638 & 9.255 & -.059 & -.083 & .642 & Female $=$ & \\
\hline BCL & 7.226 & 7.283 & 1.416 & .440 & .772 & -0.523 & \\
\hline Constant & -172.745 & -164.565 & & -8.407 & & & \\
\hline \multirow{4}{*}{\multicolumn{2}{|c|}{$\begin{array}{l}\text { MxB : Maximum Ramus Breadth. } \\
\mathrm{MnB} \text { : Minimum Ramus Breadth. } \\
\mathrm{CdH} \text { : Condylar Height. } \\
\mathrm{CrH} \text { : Coronoid Height. }\end{array}$}} & & Projective Hei & & \multirow{4}{*}{\multicolumn{3}{|c|}{$\begin{array}{l}\text { BCL : Bicodylar Length. } \\
\text { BGL : Bigonial Length. } \\
\text { MBL : Mandibular Base Length. }\end{array}$}} \\
\hline & & & Mandibular No & pth. & & & \\
\hline & & & : Mandibular Ca & ngth. & & & \\
\hline & & $\mathrm{G}$ & : Gonial Angle. & & & & \\
\hline
\end{tabular}

Table (3): Classification matrix for males and females using stepwise discriminate analysis.

\begin{tabular}{l} 
Sex \\
\cline { 2 - 5 }
\end{tabular}




\section{Discussion}

The accurate and reliable estimation of biological sex is important for the detection of unidentified human remnants [6]. The sex determination of the human remnants based on measurements and morphometry especially in missing persons and mass disasters, is more reliable and can be used as a tool in the sex determination from the skull [13]

In Egypt, few studies have been performed to investigate sexual dimorphism in hand bones $[18,19]$, foot bones [20,21], femur [22], maxillary sinus [23] and lumbar vertebra [24] and only one study on the mandible [10].

In Egypt, few studies had been conducted to produce Egyptian specific standards for accurate sex determination through the mandible. The accuracy of panoramic radiography in providing anatomic measurements has been established. The panoramic images have many advantages as low patient radiation dose, used routinely, broad coverage, short time maneuver, and the better resolution of the image taken [8]. In panoramic images, the vertical dimension is little altered in contrast to the horizontal dimension. Since all images were uniformly magnified this did not affect our results [25].

In this study, discriminate analysis was employed for eleven variables; and different models were tested as well; in males and females sample of Egyptian population to come up with the best model for sex determination. All the eleven parameters were found to be considerably differentiated between male and female; and the most dimorphic measures were coronoid height, projective height, and mandibular canal length, followed by mandibular notch depth and condylar height. Meanwhile the least variables were gonial angle and bicondylar length.

In an Egyptian study that was conducted by Kharoshah et al., [10], they studied 330 Egyptian subjects for the accuracy of six metric parameters of the mandible in sex determination using spiral CT scan. They found that only three parameters (bicondylar breadth, gonial angle and the minimum ramus breadth); to be significantly higher in males than females. Also, the best model detected by stepwise discriminate analysis used four parameters which are bicondylar breadth, gonion angle, and minimum ramus breadth and ramus length; with an overall predictive accuracy of $83.9 \%$. These findings differ from that findings declared in this study, which may account for the different tool of measurements used in either study. In this study, orthopantomograph was used as the tool of assessment for their routine wide use by clinicians and considered as the most appropriate screening tool [2]

In the stepwise discriminate analysis, four variables were selected from the eleven studied variables to give an accuracy of $76 \%$; a percent that approximately similar to different studies that was conducted in different population [4] and may be lower than other studies [26]. Comparing such parameters with model IV that was employed in this study, the accuracy of model IV was less than that used in the study conducted by Kharoshah et al., [10].

These metric measure findings were different from other population, such as Australians, where, Franklin et al., [4] found that coronoid height, ramus height and maximum length were the most significant variables and the least were the breadth and height measurements of the symphysis. Another study that was conducted in South Africa found that their findings coincide with that of Franklin and his colleagues [26].

In an Indian study, the best parameters for sex discrimination were coronoid height, condylar height and projective height; followed by maximum and minimum ramus breadth; with an overall prediction accuracy rate $80.2 \%$. The study prediction accuracy rate in females was slightly higher than males [3]; which differs from the results declared in the present study where the male accuracy prediction rate was higher than those of females. Comparing the parameters studied in model III that was employed in this Indian study, accuracy of model III was $72.7 \%$, which was lesser than same parameters used in this Indian study (accuracy $=80.2 \%$ ).

Another Indian study was conducted by Indira et al., [2] stated that minimum ramus breadth, condylar height, and projective height were the best standard used for sex identification with overall prediction accuracy rate $76 \%$.

In a third Indian study conducted by Sambhana et al., [5] using a single variable as the mandibular length or the coronoid height increased the accuracy of sexing the mandible between $50 \%$ and $74.7 \%$. While using the 10 measured variables increased the prediction rate to $75.8 \%$, with more accurately determined in females. In a previous study, the greatest sexual dimorphism was at the maximum ramus height [27] in accordance with the results of Schultze et al., [12] and Kambylafkas et al., [28] 
which assured that mandibular ramus showed differences between the sexes more than mandibular body. Similar results were reported by Samatha et al., [29] as the projective height of ramus showed the highest sexual dimorphism and least was seen with minimum ramus breadth. Projective height of ramus, maximum ramus breadth and condylar height was statistically significant.

In the current study, a formula was developed to predict the sex of the mandible from fragmentary remains with high accuracy using the most dimorphic mandibular parameters with sectioning point -0.097 . This formula could be applied to Egyptian population; however, it has some limitations as small sample size and the presence of confounders that may affect the results as malnutrition.

With respect to the previous studies, the important variables were projective height, mandibular height, mandibular width, or mandibular gonial angle on an individual basis. The current study examined all the existing important parameters put together for determining the usefulness of the ramus. The present study, found out that the projective height, coronoid height, and mandibular canal length, were highest in the sexual differences followed by condylar height and mandibular notch depth. The gonial angle and bicodylar length showed the least variables.

Although it is well established that that mandibular metric standards vary from one population to another and thus it cannot be employed similarly between racial groups [30], most of the studies, including the finding of this study, agreed that mandibular ramus is generally the most pronounced sexually dimorphic part in the mandible rather than the body [2] .

Gustafson was the first to use orthopantomography in forensic practice for the purpose of identification [31]. It has been used in comparing antemortem and postmortem dental characteristics [31] As panoramic radiography is widely used in screening and epidemiological studies [32] it will be helpful in human identification using the mandible remains especially in mass disasters.

\section{Conclusion:}

This study illustrates the potential sex discriminating power of mandible for personal identifications in forensic investigations and that mandibular ramus are generally the most pronounced sexually dimorphic part in the mandible. Mandibular ramus measurements using orthopantomographs can be used as a reliable parameter for sex determination. Further studies are needed on larger samples and different socio-environmental factors such as malnutrition; using different tools of measurements.

\section{Conflict of interest statement:}

Authors have no conflict of interest regarding this research with anyone.

\section{References}

1- GÜNAY Y. and ALTINKÖK M.: The value of the size of foramen magnum in sex determination. Journal of Clinical Forensic Medicine, 7 (3): 147-9, 2000.

2- INDIRA A.P., MARKANDE A. and DAVID M.P.: Mandibular ramus: An indicator for sex determination n- A digital radiographic study. J. Forensic. Dent. Sci., 4 (2): 58-62, 2012.

3- HU K.S., KOH K.S., HAN S.H., SHIN K.J. and KIM H.J.: Sex determination using nonmetric characteristics of the mandible in Koreans. J. Forensic. Sci., 51: 1376$82,2006$.

4- FRANKLIN D., O'HIGGINS P., OXNARD C.E. and DADOUR I.: Discriminant function sexing of the mandible of Indigenous South Africans. Forensic. Sci. Int., 179 (84): 1-5, 2008

5- SAMBHANA S., SANGHVI P., MOHAMMED R.P., SHANTA P.P., THETAY A.A.R. and CHAUDHARY V.S.: Assessment of sexual dimorphism using digital orthopantomographs in South Indians. J. Forensic. Dent. Sci., 8 (3): 180, 2016.

6- HUMPHREY L.T., DEAN M.C. and STRINGER C.B.: Morphological variation in great ape and modern human mandibles. J. Anat., 195: 491-513, 1999.

7- SAINI V., SRIVASTAVA R., RAI R.K., SHAMAL S.N., SINGH T.B. and TRIPATHI S.K.: Mandibular Ramus: An Indicator for Sex in Fragmentary Mandible. J. Forensic Sci., 56: 13-5, 2011.

8- HAZARI P., HAZARI R.S., MISHRA S.K., AGRAWAL S. and YADAV M.: Is there enough evidence so that mandible can be used as a tool for sex dimorphism? A systematic review. J. Forensic Dent. Sci., 8 (3): 174, 2016.

9- ROSING F.W., GRAW M., MARRE B., TIMME S.R., ROTHSCHILD M.A., ROTZSCHER K., et al.: Recommendations for the forensic diagnosis of sex and age from skeletons. Homo, 58 (1): 75-89, 2008.

10- KHAROSHAH M.A., ALMADANI O., GHALEB S.S. ZAKI M.K. and ABDEL FATTAH Y.A.: Sexual dimorphism of the mandible in a modern Egyptian population. Journal of Forensic and Legal Medicine, 17: 213-5, 2010.

11- CATIC' A., CELEBIC' A., VALENTIC-PERUZOVIC M., CATOVIC A. and KUNA T.: Dimensional measurements on the human dental panoramic radiographs. Coll. Antropol., 22 (Suppl): 139-45, 1998.

12- SCHULZE R., KRUMMENAUER F., SCHALLDAC F. and D'HOEDT B.: Precision and accuracy of measurements in digital radiography. Dentomaxillofac. Radiol., 29: 52-6, 2000. 
13- VODANOVIC M., DUMANCIC J., DEMO Z. and MIHELIC D.: Determination of sex by discriminant function analysis of mandibles from two Croatian archaeological sites. Acta Stomatol. Croat., 40: 263-77, 2006.

14- ALI I.M., YAMADA K. and HANADA K.: Mandibular antegonial and ramus notch depths and condylar bone change. J. Oral. Rehabil., 32 (1): 1-6, 2005.

15-BEAINI T.L., DIAS P.E.M. and MELANI R.F.H.: Exposure standards for digital and analogue dry skull orthopantomography. J. Forensic. Res., 2: 1, 2011.

16- LEE R.W.W., VASUDAVAN S., HUI D.S., PRVAN T., PETOCZ P., DARENDELILER M.A. and CISTULLI P.A.: Differences in Craniofacial Structures and Obesity in Caucasian and Chinese Patients with Obstructive Sleep Apnea, Sleep, 33 (8): 1075-80, 2010.

17- LIU T., XIA B. and GU Z.: Inferior alveolar canal course: A radiographic study. Clin. Oral. Impl. Res., 20: 1212-8, 2009.

18-ESHAK G.A., AHMED H.M. and ABDEL GAWAD E.A. Gender determination from hand bones length and volume using multidetector computed tomography: A study in Egyptian people. J. Forensic Leg. Med., 18 (6): 246-52, 2011

19- EL MORSI D.A. and AL HAWARY A.A.: Sex determination by the length of metacarpals and phalanges: X-ray study on Egyptian population. J. Forensic Leg. Med., 20 (1): 6-13, 2013

20- ZAKARIA M.S., MOHAMMED A.H., HABIB S.R. HANNA M.M. and FAHIEM A.L.: Calcaneus radiograph as a diagnostic tool for sexual dimorphism in Egyptians. J. Forensic Leg. Med., 17 (7): 378-82, 2010.

21- ABD-ELALEEM S.A., ABD-ELHAMEED M. and EWIS A.A.: Talus measurements as a diagnostic tool for sexual dimorphism in Egyptian population. J. Forensic. Leg. Med., 19 (2): 70-6, 2012.

22- GABALLAH I.F., SHEHAB A.M. and BAYOUMI K.A. Sex determination in femurs of modern Egyptians: A comparative study between metric measurements and SRY gene detection. Egyptian Journal of Forensic Sciences, 4 (4): 109-15, 2014.
23- AMIN M.F. and HASSAN E.I.: Sex identification in Egyptian population using multidetector computed tomography of the maxillary sinus. J. Forensic. Leg. Med., 19 (2): 65-9, 2012.

24- BADR EL-DINEA F.M.M. and EL-SHAFEIB M.M.: Sex determination using anthropometric measurements from multi-slice computed tomography of the 12 th thoracic and the first lumbar vertebrae among adult Egyptians. Egyptian Journal of Forensic Sciences, 5 (3): 82-9, 2015.

25- SASSOUNI V.: Dentofacial radiography in forensic dentistry. J. Dent. Res., 42: 274-302, 1963.

26- STEYN M. and ISCAN M.Y.: Sexual dimorphism in the crania and mandibles of South African whites. Forensic Sci. Int., 98: 9-16, 1998

27- DAMERA A., MOHANALAKHSMI J., YELLARTHI K. and REZWANA B.M.: Radiographic evaluation of mandibular ramus for gender estimation: Retrospective study. J. Forensic. Dent. Sci., 8 (2): 74-8, 2016.

28- KAMBYLAFKAS P., MURDOCK E., GILDA E., TALLENTS R.H. and KYRKANIDES S.: Validity of panoramic radiographs for measuring mandibular asymmetry. Angle Orthod., 76: 388-93, 20065.

29- SAMATHA K., BYAHATTI S.M., AMMANAGI R.A., TANTRADI P., SARANG C.K. and SHIVPUJE P.: Sex determination by mandibular ramus: A digital orthopantomographic study. J. Forensic. Dent. Sci., 8 (2): 95-8, 2016.

30- AYOUB F., RIZK A., YEHYA M., CASSIA A., CHARTOUNI S., ATIYEH F. and MAJZOUB Z.: Sexual dimorphism of mandibular angle in a Lebanese sample. Journal of Forensic and Legal Medicine, 16: 121-4, 2009.

31- BHATEJA S., ARORA G. and KATOTE R.: Evaluation of adult dental patterns on orthopantomograms and its implication for personal identification: A retrospective observational study. J. Forensic. Dent. Sci., 7 (1): 14-7, 2015.

32- CHOI J.W.: Assessment of panoramic radiography as a national oral examination tool: Review of the literature. Imaging Sci. Dent., 41 (1): 1-6, 2011.

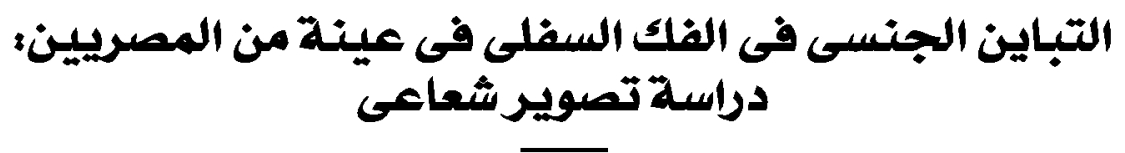

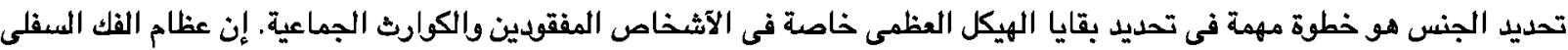

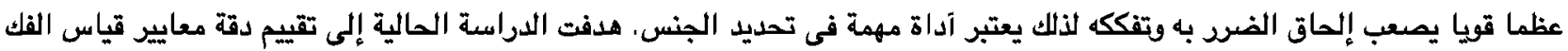

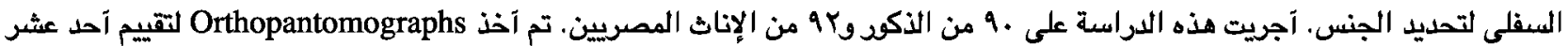

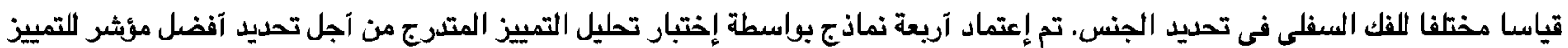

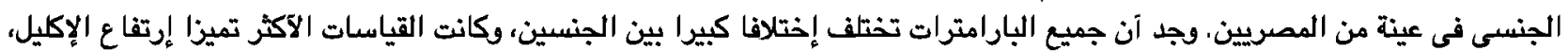

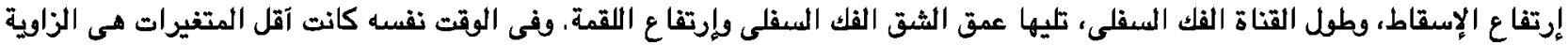
الهلالية وذاوية اللقميتن. تثبت هذه الدراسة آن قياسات الفك السفلى على الآثعة الرقمية مفيدة في تصديد الجنس.
} 